\title{
INDUCTION AND DEDUCTION
}

IN THE SCIENCES

VIENNA CIRCLE INSTITUTE YEARBOOK [2003]

11 


\title{
VIENNA CIRCLE INSTITUTE YEARBOOK [2003]
}

\author{
11
}

\author{
Institut 'Wiener Kreis' \\ Society for the Advancement of the Scientific World Conception \\ Series-Editor: \\ Friedrich Stadler \\ University of Vienna, Austria and Director, Institut 'Wiener Kreis'
}

\section{Advisory Editorial Board:}

Rudolf Haller, University of Graz, Austria, Coordinator

Martin Carrier, University of Bielefeld, Germany

Nancy Cartwright, London School of Economics, UK

Robert S. Cohen, Boston University, USA

Wilhelm K. Essler, University of Frankfurt/M., Germany

Kurt Rudolf Fischer, University of Vienna, Austria

Michael Friedman, Stanford University, USA

Maria Carla Galavotti, University of Bologna, Italy

Peter Galison, Harvard University, USA

Adolf Grübaum, University of Pittsburgh, USA

Rainer Hegselmann, University of Bayreuth, Germany

Michael Heidelberger, University of Tübingen, Germany

Jaakko Hintikka, Boston University, USA

Gerald Holton, Harvard University, USA

Don Howard, University of Notre Dame, USA

Allan S. Janik, University of Innsbruck, Austria

Richard Jeffrey, Princeton University, USA

Andreas Kamlah, University of Osnabrück, Germany

Eckehart Köhler, University of Vienna, Austria

Anne J. Kox, University of Amsterdam, The Netherlands

Elisabeth Leinfellner, University of Vienna, Austria

Werner Leinfellner, Technical University of Vienna, Austria

James G. Lennox, University of Pittsburgh, USA

Brian McGuinness, University of Siena, Italy

Kevin Mulligan, Université de Genève, Switzerland

Elisabeth Nemeth, University of Vienna, Austria

Julian Nida-Rümelin, University of Göttingen, Germany

Helga Nowotny, ETH Zürich, Switzerland

Erhard Oeser, University of Vienna, Austria

Joëlle Proust, École Polytechnique CREA Paris, France

Alan Richardson, University of British Columbia, CDN

Peter Schuster, University of Vienna, Austria

Jan Šebestík, CNRS Paris, France

Karl Sigmund, University of Vienna, Austria

Hans Sluga, University of California at Berkeley, USA

Elliott Sober, Stanford University, USA

Antonia Soulez, Université de Paris 8, France

Wolfgang Spohn, University of Konstanz, Germany

Christian Thiel, University of Erlangen, Germany

Walter Thirring, University of Vienna, Austria

Thomas E. Uebel, University of Manchester, UK

Georg Winckler, University of Vienna, Austria

Ruth Wodak, University of Vienna, Austria

Jan Woleński, Jagiellonian University, Cracow, Poland

Anton Zeilinger, University of Vienna, Austria

\author{
Honorary Consulting Editors: \\ Kurt E. Baier \\ Francesco Barone † \\ C.G. Hempel $\dagger$ \\ Stephan Körner † \\ Saul A. Kripke \\ Henk Mulder $\dagger$ \\ Arne Naess \\ Paul Neurath $\uparrow$ \\ Willard Van Orman Quine + \\ Marx W. Wartofsky $\dagger$
}

\section{Review Editor:}

Michael Stöltzner, University of Bielefeld, Germany

\section{Editorial Work/Layout/Production:}

Laurence C. Fauth

Hartwig Jobst

Robert Kaller

Camilla R. Nielsen

\section{Editorial Address:}

Institut 'Wiener Kreis'

Museumstrasse 5/2/19, A-1070 Wien, Austria

Tel.: +431/5261005 (international) or $01 / 5261005$ (national)

Fax.: +431/5248859 (international) or 01/5248859 (national)

email: ivc.zuef@univie.ac.at

homepage: http://univie.ac.at/ivc/

The titles published in this series are listed at the end of this volume. 


\title{
INDUCTION AND DEDUCTION IN THE SCIENCES
}

\author{
Edited by \\ FRIEDRICH STADLER \\ University of Vienna, \\ and Institute Vienna Circle, Austria
}

Springer Science+Business Media, B.V. 
A C.I.P. Catalogue record for this book is available from the Library of Congress.

ISBN 978-90-481-6555-1 ISBN 978-1-4020-2196-1 (eBook)

DOI 10.1007/978-1-4020-2196-1

Series ISSN 0929-6328

Printed on acid-free paper

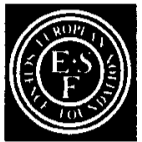

Gedruckt mit Förderung der European Science Foundation Printed with financial support of the European Science Foundation

The European Science Foundation (ESF) acts as a catalyst for the development of science by bringing together leading scientists and funding agencies to debate, plan and implement pan-European scientific and science policy initiatives.

ESF is the European association of 76 major national funding agencies devoted to scientific research in 29 countries. It represents all scientific disciplines: physical and engineering sciences, life and environmental sciences, medical sciences, humanities and social sciences. The Foundation assists its Member Organisations in two main ways. It brings scientists together in its EUROCORES (ESF Collaborative Research Programmes), Scientific Forward Looks, Programmes, Networks, Exploratory Workshops and European Research Conferences to work on topics of common concem including Research Infrastructures. It also conducts the joint studies of issues of strategic importance in European science policy.

It maintains close relations with other scientific institutions within and outside Europe. By its activities, the ESF adds value by cooperation and coordination across national frontiers and endeavours, offers expert scientific advice on strategic issues, and provides the European forum for science.

\section{Gedruckt mit Förderung des Österreichischen Bundesministeriums} für Bildung, Wissenschaft und Kultur

Printed with financial support of the Austrian Ministry for Education, Science and Culture

In cooperation with the University of Vienna, Center for Interdisciplinary Research / Zentrum für überfakultäre Forschung

All Rights Reserved

(C) The Editor(s) (if applicable) and The Author(s), under exclusive licence to Springer Science+Business Media B.V. 2004, corrected publication 2020.

Originally published by Kluwer Academic Publishers in 2004.

Softcover reprint of the hardcover 1st edition 2004

No part of this work may be reproduced, stored in a retrieval system, or transmitted in any form or by any means, electronic, mechanical, photocopying, microfilming, recording or otherwise, without written permission from the Publisher, with the exception of any material supplied specifically for the purpose of being entered and executed on a computer system, for exclusive use by the purchaser of the work. 


\section{EDITORIAL}

The articles in the general part of this Vienna Circle Institute Yearbook "Induction and Deduction in the Sciences" document the invited contributions to the $2^{\text {nd }}$ international workshop of the European Science Foundation's (ESF) Scientific Network on "Historical and Contemporary Perspectives of Philosophy of Science in Europe". This event, which was organised by the Vienna Circle Institute, took place July 7-9, 2002 at the University of Vienna. The first workshop of this network on main issues, methods and results in history and philosophy of science in an European context was held at the Bertinoro Conference Centre of the University of Bologna from September 30 to October 2, 2001. The network is run by a coordinating committee consisting of Maria Carla Galavotti (Bologna, Italy) who has served as chairperson, Aristides Baltas (Athens, Greece), Donald Gillies (London, UK), Theo Kuipers (Groningen, The Netherlands), Ilkka Niiniluoto (Helsinki, Finland), Michel Paty (Paris, France), Miklos Rédei (Budapest, Hungary), Friedrich Stadler (Vienna, Austria), and Gereon Wolters (Konstanz, Germany). The proceedings of the first workshop have been published in a volume under the title Observation and Experiment in the Natural and Social Sciences, edited by Maria Carla Galavotti with Kluwer Academic Publishers. ${ }^{1}$

The third workshop on "Laws and Models in Science" took place at King's College London, September 7-9, 2003 and addressed problems of the structure of science, in particular the role played by theories, laws and models in several scientific fields and their different applications. Its proceedings will be published 2004 in a special volume of the "King's College Publications", edited by Donald Gillies.

The general aim of the ESF network from 2000 to 2003 was to identify the main features of philosophy of science in Europe today, in a spirit of continuity with a tradition that originated in Logical Empiricism (Vienna Circle and Berlin Group) in Central Europe in the first decades of the last century. Since the heyday of scientific philosophy new archival material and research accompanied by extensive transatlantic exchanges has brought forth new perspectives and results in this interdisciplinary field. These contributions have contributed to a clarification and better understanding of the nature of scientific knowledge from a historical and philosophical point of view. ${ }^{2}$

\footnotetext{
' Maria Carla Galavotti (ed.), Observation and Experiment in the Natural and Social Sciences. Kluwer: Dordrecht-Boston-London 2003. (= Boston Studies in the Philosophy of Science, Vol.232).

${ }^{2} \mathrm{Cf}$. the list of the publications of the Vienna Circle Institute: http://www.univie.ac.at/ivc/
} 
The articles in this volume deal with the main inferential methods that can be applied to different kinds of experimental evidence. These contributions aim at removing the traditional opposition between inductivists and deductivists (e.g., by focusing on abduction) in order to explore the different methods of explanation and justification in the formal, natural and social sciences in different contexts and with different objectives.

This volume also includes critical comments made by leading scholars on methods of the sciences, especially on induction, deduction, abduction, laws, probability and explanation, ranging from logic, mathematics, natural to the social sciences. They present a highly topical pluralist re-evaluation of methodological and foundational procedures and reasoning, e.g. focusing on Bayesianism and Artificial Intelligence.

The workshop in Vienna was funded by the ESF and the organisers, the Vienna Circle Institute together with the University of Vienna, Center for Interdisciplinary Research and Department of Contemporary History. The conference and publication were made possible by the support of the editorial team of Vienna Circle Institute with Gloria Sultano, Daria Mascha, Robert Kaller, Laurence C. Fauth, Camilla R. Nielsen and Hartwig Jobst, all of whom I would like to thank for their professional cooperation. The publication of each Yearbook is supported by the Austrian Ministry of Education, Science and Culture, for which we are grateful as well.

We have retained the format of our series in the $11^{\text {th }}$ volume of the Vienna Circle Yearbook with the announcement of our activities, documentation and a review section presenting recent publications on logical empiricism and related fields, for which I would like to thank our review editor Michael Stöltzner.

We have also included an obituary on Richard Jeffrey, one of the most important and distinguished $20^{\text {th }}$ century philosophers of science who supported IVC from the beginning as a member of the scientific board and contributor to its conferences. We will remember his life and extraordinary work in the tradition of Logical Empiricism in the spirit of his open-minded and creative scholarship.

Vienna, October 2003

\author{
Friedrich Stadler \\ (University of Vienna, \\ and Vienna Circle Institute)
}

The original version of this book was revised. The Copyrightholdername has been corrected. 


\section{TABLE OF CONTENTS}

\section{A. INDUCTION AND DEDUCTION IN THE SCIENCES}

I.

FRIEDRICH STADLER: Induction and Deduction in the Philosophy of Science:

a Critical Account since the Methodenstreit

MALACHI HACOHEN: Historicizing Deduction: Scientific Method, Critical

Debate, and the Historian

II.

THEO A.F. KUIPERS: Inference to the Best Theory, rather than Inference to the Best Explanation - Kinds of Abduction and Induction 25

ADAM GROBLER: The Significance of Explanatory Considerations

III.

ILKKA NIINILUOTO: Truth-seeking by Abduction 57

STATHIS PSILLOS: Inference to the Best Explanation and Bayesianism 83

IV.

JOKE MEHEUS: Adaptive Logics and the Integration of Induction and

Deduction

MATTI SinTONEN: Argument, Inference and Reasoning - Integrating Induction and Deduction

V.

WOLFGANG SPOHN: Laws are Persistent Inductive Schemes 135

ECKEHART KÖHLER: Physical Intuition as Inductive Support 
VI.

PETER ClaRK: Frege, Neo-Logicism and Applied Mathematics

Michel PATY: Remarks About a "General Science of Reasoning"

JEAN-JACQUES SZCZECINIARZ: Two Questions About the Revival of

Frege's Programme

VII.

DONALD GILLIES: Handling Uncertainty in Artificial Intelligence, and the Bayesian Controversy

STEPHAN HARTMANN: Artificial Intelligence and Its Methodological Implications

VIII.

HANS RoTT: Supplying Planks for Neurath's Boat: Can Economists Meet the Demands of the Dynamics of Scientific Theories? 225

NILS-ERIC SAHLIN: Informational Economy and Creativity 247

IX.

I. GRATTAN-Guinness: The Place of the Notion of Corroboration in Karl Popper's Philosophy of Science 251

LADISLAV KVASZ: How can a Falsified Theory Remain Corroborated? 263

$\mathrm{X}$.

KARL MILFORD: Inductivism in $19^{\text {th }}$ Century German Economics 273

DAVID MILLER: The Uniformity of Nature: What Purpose does it Serve? 293 
SyBILLA NIKOLOW: Planning, Democratization and Popularization with ISOTYPE, ca. 1945: a Study of Otto Neurath's Pictorial Statistics with the Example of Bilston, England

\section{REVIEWS}

Paolo Parrini, Wesley C. Salmon \& Merrilee H. Salmon (eds.), Logical Empiricism: Historical \& Contemporary Perspectives. Pittsburgh: University of Pittsburgh Press, 2003.

(Christopher Pincock)

C. Wayne Mayhall, On Logical Positivism, Wadsworth Philosophical Topics, Belmont, 2003.

(Matthias Neuber)

C. Wayne Mayhall, On Carnap, Wadsworth Philosopher Series, Wadsworth / Thomson Learning, Belmont USA, 2002.

(Christian Damböck)

Jean-Pierre Cometti and Kevin Mulligan, La philosophie autrichienne de Bolzano à Musil. Histoịre et actualité, Paris: J. Vrin, 2001.

(Anastasios Brenner)

Steven Beller (ed.), Rethinking Vienna 1900. Berghahn Books, New YorkOxford 2001.

(Kurt Rudolf Fischer)

Eckart Menzler-Trott, Gentzens Problem. Mathematische Logik im nationalsozialistischen Deutschland, Birkhäuser: Basel-Boston-Berlin 2001. (Matthias Wille) 


\section{ACtivities OF THE INSTitute VienNa CiRCLE}

Activities 2003 347

Preview 2004 350

\section{OBITUARY}

Remembering Dick Jeffrey (1926-2002)

(Maria Carla Galavotti)

Correction to: Induction and Deduction in the Sciences $\mathrm{Cl}$

Index of Names 355 